\title{
REPEATED ACCELERATION ACTIVITY IN COMPETITIVE YOUTH SOCCER
}

\author{
David J. Barron, ${ }^{1, A, B, C, D}$ Steve Atkins, ${ }^{2, \text { A }}$ Chris Edmundson, ${ }^{2, \text { A }}$ Dave Fewtrell ${ }^{2, \text { A }}$ \\ ${ }^{1}$ Myerscough College, Bilsborrow, Preston, Lancashire, UK \\ ${ }^{2}$ Division of Sport and Exercise and Nutritional Sciences, University of Central Lancashire, Preston, UK

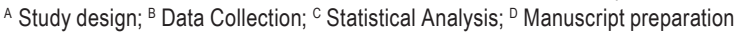 \\ Address for corpespondence: \\ David Barron MSc. \\ Department of Sport, Myerscough College, St Michaels Road, Bilsborrow, Preston, Lancashire, UK, PR3 ORY \\ E-mail: dbarron@myerscough.ac.uk
}

\begin{abstract}
Ahstract. Soccer match-play is increasingly characterised by short, high-speed bursts reliant on the ability to accelerate. Performance is impaired after peak acceleration activity and during the second half and may compromise a player's effectiveness. To date, information about repeated acceleration sequences is lacking but would provide further insight into high-speed activity during competition. This study examined repeated acceleration ability (RAA) using GPS $(5 \mathrm{~Hz})$ and accelerometer $(100 \mathrm{~Hz})$, during 14 competitive youth soccer matches from the 2014-2015 season. Results showed that RAA profiles were relatively homogeneous, and there were no significant differences between playing positions. RAA activity was also relatively stable between playing halves and only the activity of forwards declined significantly. In summary, this study suggests that RAA is a generic requirement of match-play at this level but presents a specific focus for conditioning regimens.
\end{abstract}

Key WOPlls: soccer, youth, repeated acceleration ability, RAA, GPS, performance analysis

\section{Introduction}

Recent studies have described the evolution in the physical demands of competition, and increasingly the modern game is punctuated by a greater number of short high-speed bursts (Wallace, Norton, 2014). Between 2006/07-2012/13, total sprint distance increased $~ 35 \%$; facilitated by a decrease in individual sprint distance and an increase in the number of sprints. Also, the proportion of explosive sprints has increased $\sim 10 \%$ (Barnes, Archer, Buchheit, Bradley, 2014) emphasising the importance of acceleration (Wallace, Norton, 2014). Research is unequivocal that maximal accelerations are more frequent than maximal sprints (Varley, Aughey, 2012) and that superior acceleration may present a competitive advantage (Lockie, Murphy, Knight, de Jonge, 2011; Little, Williams, 2005).

Given the importance of accelerating, the ability to withstand their fatiguing effect is essential. Reductions in acceleration capacity are found between halves and transiently during the game. Between playing halves, a decline is reported in the number of efforts (Ingebrigtsen, Terje, Hjelde, Drust, Wisloff, 2015; Russell et al., 2014; Terje, Ingebrigtsen, Gertjan, Harvard, Wisloff, 2015) and the cumulative distance (Terje et al., 2015; Akenhead, Hayes, 
Thompson, Duncan, 2013; Barron, Atkins, Edmundson, Fewtrell, 2014). Acceleration activity can be reasonably expected to be unevenly distributed throughout a game and lead to very intense periods of repeated activity. During one study, peak acceleration activity resulted in a $\sim 10 \%$ reduction in subsequent activity lasting for $\sim 10$ minutes (Akenhead et al. 2013). Impaired acceleration ability could, therefore, be expected to impact on the player's effectiveness and reduce the team's offensive and/or defensive potency.

Previous analysis of the most intense periods of match-play has led to the development of repeated sprint activity (RSA) training and testing protocols, yet consensus is lacking whether this is a key component. Some studies have found very limited evidence of RSA during match-play (Buchheit, Mendez-Villanueva, Simpson, Bourdon, 2010; Carling, Le Gall, Dupont, 2012; Barberó-Álvarez et al., 2014) and, it would appear that measuring repeated acceleration activity (RAA) would be more insightful.

RAA is defined as three consecutive acceleration efforts $\left(>1.5 \mathrm{~m} \cdot \mathrm{s}^{-2}\right)$ interspersed with a maximum of 45 seconds, and the only study to date was conducted on elite field and assistant referees (Barberó-Álvarez et al., 2014). Analysis of the RAA activity of outfield players would further enhance the understanding of the rigours of competition and inform conditioning programmes. The aim of this study was to investigate RAA activity during subelite youth competition.

\section{Method}

\section{Participants}

Sixty-one well-trained sub - elite youth soccer players (17.3 \pm 0.9 years, $176.93 \pm 4.31 \mathrm{~cm} ; 63.96 \pm 4.76 \mathrm{~kg}$ ) volunteered for the study. Written consent was provided in accordance with the procedures outlined in the Declaration of Helsinki. Approval was granted by the School of Sport, Tourism and Outdoors ethics committee at the University of Central Lancashire. Players were classified by playing position, including; wide defenders (WD = 13), central defenders $(C D=17)$, central midfielders $(C M F=11)$, wide midfielders $(W M F=10)$ and forwards $(F W=10)$. 14 home English College fixtures were monitored during the competitive phase of the 2014-2015 season. All games were played on a full-size synthetic 3G surface; a 4-2-3-1 formation was preferred and only players completing the full 90 minutes in the same playing position were included for analysis.

\section{Procedure}

Portable $5 \mathrm{~Hz}$ GPS units (Catapult Sports, Minimax) equipped with a $100 \mathrm{~Hz}$ accelerometer were located in a custom built vest and harnessed securely between the upper shoulder blades. GPS units were switched on 10 minutes before use to allow satellite locking consistent with manufacturer's guidelines. Horizontal dilution of precision (HDOP) indicates accuracy of GPS in a horizontal plane and optimum satellite availability (HDOP $=0.0)$ is where one satellite is directly overhead with a minimum of four spaced equally around the horizon. During these trials, HDOP ranged $0.76-1.32$ which is a good signal (Catapult Sports).

\section{Analysis}

RAA was defined as three consecutive accelerations $>1.5 \mathrm{~m} \cdot \mathrm{s}-2$ interspersed with a maximum of 45 seconds. Data was uploaded to Catapult Sprint software (version 5.1.7), and files were filtered to exclude non - game activity, producing $2 \times 45$ minute periods. 
All data was tested for normality using a Kolmogorov-Smirnov and Levene's test established homogeneity. One way ANOVA was used to detect the main differences in the number of RAA bouts and differences between playing positions and playing halves. Significant main effects were investigated with post hoc Bonferroni - corrected multiple comparisons. Non - parametric data was assessed using a Kruskal - Wallis test. Statistical significance was accepted at $p \leq 0.05$ and Pearson's Correlation Coefficient measured effect size where $r=0.10$ (small effect); $r=0.30$ (medium effect) and $r=0.50$ (large effect). All statistical procedures were completed using SPSS 20.0 (SPSS Inc. Chicago, USA).

\section{Results}

There was a significant main effect of playing position on the total number of RAA bouts, but post hoc testing revealed no significant differences. Confidence interval data shows that wide players tended to complete more RAA bouts than central positions. There was no significant differences in the number of efforts per bout or recovery duration (see Table 1).

Table 1. Summary of RAA activity by playing position

\begin{tabular}{|c|c|c|c|c|c|c|c|c|}
\hline \multirow{2}{*}{ Position } & \multicolumn{2}{|c|}{ Total bouts } & \multicolumn{2}{|c|}{ Efforts per bout } & \multicolumn{2}{|c|}{ Recovery per effort (secs) } & \multicolumn{2}{|c|}{ Recovery per bout (secs) } \\
\hline & mean $( \pm S D)$ & $95 \% \mathrm{Cl}$ & mean $( \pm S D)$ & $95 \% \mathrm{Cl}$ & mean $( \pm S D)$ & $95 \% \mathrm{Cl}$ & mean $( \pm S D)$ & $95 \% \mathrm{Cl}$ \\
\hline WD & $9.15(3.71)$ & $6.90-11.39$ & $3.78(0.50)$ & $3.47-4.08$ & $19.75(2.63)$ & $18.16-21.35$ & $477.09(353.72)$ & $263.34-690.84$ \\
\hline$C D$ & $5.56(3.32)$ & $3.89-7.21$ & $3.52(0.98)$ & $3.03-4.01$ & $19.23(5.85)$ & $16.32-22.15$ & $515.34(394.45)$ & $319.19-711.50$ \\
\hline CMF & $5.46(3.86)$ & $2.86-8.04$ & $3.16(1.09)$ & $2.42-3.90$ & $18.58(6.97)$ & $13.90-23.26$ & $418.71(323.55)$ & $201.35-636.07$ \\
\hline WMF & $10.50(7.16)$ & $5.37-15.63$ & $3.68(0.54)$ & $3.29-2.42$ & $18.48(2.01)$ & $17.03-19.92$ & $385.15(184.37)$ & $253.26-517.04$ \\
\hline FW & $6.80(3.94)$ & $3.98-9.61$ & $3.75(0.95)$ & $3.33-4.18$ & $16.35(4.01)$ & $13.47-19.22$ & $562.74(257.78)$ & $253.26-517.04$ \\
\hline All & $7.29(4.70)$ & $6.09-8.48$ & $3.58(0.81)$ & $3.36-3.78$ & $18.64(4.80)$ & $17.42-19.86$ & $476.82(321.85)$ & $395.08-558.56$ \\
\hline \multirow{2}{*}{ Sig. } & \multicolumn{2}{|c|}{$p=0.02$} & \multicolumn{2}{|c|}{$p=0.37$} & \multicolumn{2}{|c|}{$p=0.53$} & \multicolumn{2}{|c|}{$p=0.72$} \\
\hline & \multicolumn{2}{|c|}{$r=0.43$} & \multicolumn{2}{|c|}{$r=0.30$} & \multicolumn{2}{|c|}{$r=0.22$} & \multicolumn{2}{|c|}{$r=0.19$} \\
\hline
\end{tabular}

RAA activity was relatively stable between playing halves, and only the activity of FW declined significantly (see Table 2). Collapsed means showed there was no significant decrease between halves, in the number of efforts per RAA bout ( $2.52 \pm 1.85$ vs. $2.40 \pm 1.97, p=0.49, r=0.05$ ) or the recovery interval between efforts ( 13.21 secs \pm 10.93 vs. 12.22 secs $\pm 10.90, p=0.33, r=0.07$ ).

Table 2. Number of RAA bouts between match halves by playing position (mean \pm SD)

\begin{tabular}{lccccc} 
& WD & CD & CMF & WMF & FW \\
\cline { 2 - 6 } First half & $4.65( \pm 1.52)$ & $2.94( \pm 0.97)$ & $2.64( \pm 0.85)$ & $5.25( \pm 1.80)$ & $4.44( \pm 1.47)$ \\
Second half & $4.50( \pm 1.46)$ & $2.62( \pm 0.85)$ & $2.82( \pm 0.91)$ & $5.25( \pm 1.80)$ & $2.85( \pm 0.93)$ \\
\hline \multirow{2}{*}{ Sig. } & $p=0.82$ & $p=0.46$ & $p=0.76$ & $p=1.00$, & $p=0.04$ \\
& $r=0.04$ & $r=0.10$ & $r=0.14$ & $r=0.00$ & $r=0.46$ \\
\hline
\end{tabular}




\section{Discussion}

This study provides evidence of repeated acceleration activity by sub-elite youth soccer players, during competition. Across all positions, the mean number of RAA bouts was $7.09( \pm 4.70)$, and there was a main effect of playing position, although there were no significant positional differences identified. There was a trend for wide players to complete more efforts than central, and a moderate effect size $(r=0.43)$ provides justification for further investigation. On average the number of efforts per RAA bout was $3.58( \pm 0.81)$ and again, wide players tended to complete more efforts per bout, compared to central players. The lack of significant differences indicates that the RAA activity was comparable, suggesting it is a crucial attribute for all positions.

Research of RAA is scant, but amongst top - level referees, there were $7.0( \pm 3.9)$ RAA bouts and $3.9( \pm 1.5)$ efforts per bout during match - play (Barberó-Álvarez et al., 2014). Despite the similarities to this study, comparison is done so cautiously because of the fundamental difference in roles between referees and players. Nevertheless, we conclude that RAA may be a useful measure of high-speed performance in youth soccer. Previously, repeated sprint ability has been proposed as a crucial element of performance (Di Mascio, Bradley, 2013), however, limited RSA activity reported by our group (Barron et al., 2014) and others contradicts these claims (Buchheit et al. 2010; Carling et al. 2012; Barberó-Álvarez et al., 2014) suggesting RAA is a more useful measure.

Recently the link between high speed running and successful performance has been challenged (Bradley et al., 2013). Increasing numbers of short, high-speed bursts are observed (Wallace, Norton, 2014; Barnes et al., 2014) reliant on high rates of acceleration. Maximum accelerations are more frequent than maximum sprints (Varley, Aughey, 2013; Ingebrigtsen et al., 2015; Russell et al., 2015) and are completed at low velocities (Osgnach, Poser, Di Prampero, Bernardini, Rinaldo, 2010), therefore the efficacy of using the number of sprints, or a distance-based index as a performance measure, is questionable (Terje et al., 2015).

Confidence interval data shows that the number of efforts per RAA bout can reach far higher values than suggested by the mean. Although our study did not examine the impact of RAA activity, the fatiguing effect of elevated activity could be expected to negatively affect subsequent work-rate because neuromuscular fatigue is strongly linked to alterations in the force generation capacity of skeletal muscle (Rahnama, Reilly, Lees, Graham Smith, 2003; Rampinini et al., 2011). In a separate study, acceleration capacity was impaired following peak activity and a decrement of $\sim 11 \%$ in high magnitude accelerations persevered for $\sim 10$ minutes (Akenhead et al., 2013).

During an U-15 competition featuring five games $(2 \times 25$ mins $)$ in three days, the acceleration profile was significantly reduced in the latter games, despite no change in maximum sprinting speed or locomotor activities (Arruda et al., 2015). Similarly, there were no reductions in sprints or high speed running during a similar period, in England (Odetoyinbo, Wooster, Lane, 2007), Scotland (Dupont et al., 2010), Spain (Rey, Lago-Peñas, LagoBallesteros, Casais, Dellal, 2010) and France (Carling, Dupont, 2011). These findings may appear inconsistent yet, a fatigued player could be expected to take longer to reach target speed and result in running distance being maintained, masking the impairment of acceleration performance.

Impaired acceleration ability could be supposed to impact on the players ability to move efficiently in tight areas, create space to receive the ball or to press an opponent, for example. However, reductions in physical performance are not necessarily mirrored by declines in technical performance. A comparison of congested and non-congested periods showed the number of passes, the percentage of duels won and touches per possession were unchanged at the elite level (Carling, Dupont, 2011). However, amongst semi - professionals, there were significant declines in passing accuracy, after repeated sprint activity (McMorris, Rayment, 2007), leading the authors to conclude 
that high-speed exercise deleteriously affects motor control in an amateur population. The ability to resist fatigue is crucial if a player can perform efficient and precise actions continually during competition (Stone, Oliver, 2009), and the superior fitness of the elite players may explain these differences. In this case, it emphasises the need for amateurs to develop their resistance to repeated accelerations.

Unlike technical performance, tactical performance did decline during fixture dense periods, and players exhibited less positional synchronisation at the elite level (Folgado, Duarte, Fernandes, Sampaio, 2014). The field of analytics defines performance as how players, collectively and individually, adapt to the ever-changing configurations of match-play to gain a competitive advantage (Folgado et al., 2014; Gréhaigne, Godbout, Bouthier, 1999). Facing higher tiered opponents required greater synchronisation, and this produced significantly more high $\left(14.4-19.7 \mathrm{~km} \cdot \mathrm{hr} r^{-1}\right)$ and very high speed $\left(>19.8 \mathrm{~km} \cdot \mathrm{hr} r^{-1}\right)$ running. The disparity between the numbers of accelerations and the number of sprints (Varley, Aughey, 2013; Ingebrigtsen et al., 2015), implies effective synchronisation is also dependent on the ability to accelerate repeatedly. By extension, impairment in the ability to accelerate may result in less synchronisation and reduce a team's offensive and defensive potency.

An important limitation of this study is the ability of the $5 \mathrm{~Hz}$ Minimax GPS to measure instantaneous changes of speed during acceleration. Underestimations of -5 to $-9.6 \%$ were reported in comparison to a laser (Varley, Fairweather, Aughey, 2012) implying this data is the minimum values achieved during match - play and that bouts of RAA may be more numerous. Also, due to the nature of the study, it is not possible to directly link a bout of RAA with a key game event. Future research could seek to investigate these links and thereby bridge the gap between physical and technical performance. We acknowledge the relatively small sample size used in this study, but the evidence presented provides sufficient justification to warrant further investigations of RAA in other levels of competition.

\section{Conclusions}

In summary, the capacity to accelerate repeatedly is crucial for all playing positions, but probably more important for wide players. The evidence of RAA in this study highlights spells of intense activity that may not be reflected by measures of total distance or the total number of accelerations. Elevated periods of activity lead to time-dependent impairments in physical capacity that may compromise a player's effectiveness. Coaches should, therefore, consider including activities featuring repeated accelerations to optimise preparedness for competition.

\section{Acknowledgements}

This work received no external funding.

\section{References}

Akenhead, R., Hayes, P., Thompson, K., Duncan, F. (2013). Diminutions of acceleration and deceleration output during professional football match-play. Journal of Science and Medicine in Sport, 16 (6), 556-561. DOI: 10.1016/J.JSAMS.2012.12.005.

Arruda, A., Carling, C., Zaneti, V., Aoki, M., Coutts, A., Moreira, A. (2015). Effects of a very congested match schedule on bodyload impacts, accelerations and running measures in youth soccer players. International Journal of Sports Physiology and Performance, 10 (2), 248-252. DOI: 10.1123/IJSPP.2014-0148.

Barberó-Álvarez, J., Carlow, J., Boullosa, D., Nakamura, F., Andrin, G., Weston, M. (2014). Repeated acceleration ability (RAA): a new concept with reference to top-level field and assistant referees. Asian Journal of Sports Medicine, 5 (1), 63-66. 
Barnes, C., Archer, D., Buchheit, M., Bradley, P. (2014). The evolution of physical and performance parameters in the English Premier League. International Journal of Sports Medicine, 35, 1-6. DOI: 10.1055/S-0034-1375695.

Barron, D.J., Atkins, S., Edmundson, C., Fewtrell, D. (2014). Accelerometer derived load according to playing position in competitive youth soccer. International Journal of Performance Analysis in Sport, 14 (3), 734-743.

Bradley, P., Carling, C., Gomez-Diaz, A., Hood, P., Ade, J., Boddy, M. (2013). Match performance and physical capacity of players in the top three competitive standards of English professional soccer. Human Movement Science, 32 (4), 808-821. DOI: 10.1016/J. HUMOV.2013.06.002.

Buchheit, M., Mendez-Villanueva, M., Simpson, M., Bourdon, P. (2010). Repeated-sprint sequences during youth soccer matches. International Journal of Sports Medicine, 31 (10), 709-716. DOI: 10.1055/S-0030-1261897.

Carling, C., Dupont, G. (2011). Are declines in physical performance associated with a reduction in skill-related performance during professional soccer match-play? Journal of Sports Science, 29 (1), 63-71. DOI: 10.1080/02640414.2010.521945.

Carling, C., Le Gall, F., Dupont, G. (2012). Analysis of repeated high-intensity running performance in professional soccer. Journal of Sports Sciences, 30 (4), 325-336. DOI: 10.1080/02640414.2011.652655.

Di Mascio, M., Bradley, P. (2013). Evaluation of the most high intensity running period in English FA Premier League soccer matches. Journal of Strength and Conditioning Research, 27 (4), 909-915. DOI: 10.1519/JSC.0B013E31825FF099.

Dupont, G., Nedelec, M., Berthoin, S., McCall, A., McCormack, D., Wisloff, U. (2010). Effect of 2 soccer matches in a week on physical performance and injury rate. American Journal of Sports Medicine, 38 (9), 1752-1758. DOI: 10.1177/0363546510361236.

Folgado, H., Duarte, R., Fernandes, O., Sampaio, J. (2014). Competing with lower level opponents decreases intra-team movement synchronization and time-motion demands during pre-season soccer matches. PLOS one, 9, 5. DOI: 10.1371/JOURNAL. PONE.0120461.

Gréhaigne, J., Godbout, P., Bouthier, D. (1999). The foundations of tactics and strategy in team sports. Journal of Teaching in Physical Education, 18 (2), 159-174.

Ingebrigtsen, J., Terje, D., Hjelde, G., Drust, B., Wisloff, U. (2015). Acceleration and sprint profiles of a professional elite football team in match-play. European Journal of Sport Science, 15 (2), 101-110. DOI: 10.1080/17461391.2014.933879.

Little, T., Williams, A. (2005). Specificity and acceleration, maximum speed and agility in professional soccer players. Journal of Strength and Conditioning Research, 19 (1), 76-78.

Lockie, R., Murphy, A., Knight, T., de Jonge, J. (2011). Factors that differentiate acceleration ability in field sport athletes. Journal of Strength and Conditioning Research, 10, 2704-2714. DOI: 10.1519/JSC.0B013E31820D9F17.

McMorris, T., Rayment, T. (2007). Short-duration, high-intensity exercise and performance of a sports-specific skill: a preliminary study. Perceptual and Motor Skills, 105 (2), 523-530.

Odetoyinbo, K., Wooster, B., Lane, A. (2007). The effect of a succession of matches on the activity profiles of professional soccer players. Journal of Sport Science and Medicine, 10, 16-17.

Osgnach, C., Poser, S., Di Prampero, P., Bernardini, R., Rinaldo, R. (2010). Energy cost and metabolic power in elite soccer: A new match analysis approach. Medicine and Science in Sports and Exercise, 42 (1), 170-178. DOI: 10.1249/MSS.0B013E3181AE5CFD.

Rahnama, N., Reilly, T., Lees, A., Graham-Smith, P. (2003). Muscule fatigue induced by exercise simulating the work rate of competitive soccer. Journal of Sports Sciences, 21 (11), 933-942.

Rampinini, E., Bosio, A., Ferraresi, I., Petruolo, A., Morrelli, A., Sassi, A. (2011). Match-related fatigue in soccer players. Medicine and Science in Sport and Exercise, 43 (11), 2161-2170. DOI: 10.1249/MSS.0B013E31821E9C5C.

Rey E., Lago-Peñas, C., Lago-Ballesteros, J., Casais, L., Dellal, A. (2010). The effect of a congested fixture period on the activity of elite soccer players. Biology of Sport, 27 (3), 181-185.

Russell, M., Sparkes, W., Northeast, J., Cook, C., Love, T., Bracken, R. (2014). Changes in acceleration and deceleration capacity throughout professional soccer match-play. Journal of Strength and Conditioning Research. Advanced online publication.

Stone, K., Oliver, J. (2009). The effect of 45 minutes of soccer-specific exercise on the performance of soccer skills. International Journal of Sports Physiology and Performance, 4 (2), 163-175.

Terje, D., Ingebrigtsen, J., Gertjan, E., Harvard, G., Wisloff, U. (2016). Playerload, acceleration and deceleration during 45 competitive matches of elite soccer. Journal of Strength and Conditioning Research, 30 (2), 351-359. DOI: 10.1519/JSC.0000000000001063.

Varley, M., Aughey, R. (2013). Acceleration profiles in elite Australian soccer. International Journal of Sports Medicine, 34 (1), $34-39$. DOI: $10.1055 /$ S-0032-1331776. 
Varley, M., Fairweather, I., Aughey, R. (2012). Validity and reliability of GPS for measuring instantaneous velocity during acceleration, deceleration and constant motion. Journal of Sports Sciences, 30 (2), 121-127. DOI: 10.1080/02640414.2011.627941.

Wallace, J., Norton, K. (2014). Evolution of World Cup soccer finals 1966-2010: game structure, speed and play patterns. Journal of Science and Medicine in Sport, 17 (2), 223-228. DOI: 10.1016/J.JSAMS.2013.03.016.

Cite this article aS: Barron, D.J., Atkins, S., Edmundson, C., Fewtrell D. (2016). Repeated Acceleration Activity in Competitive Youth Soccer. Central European Journal of Sport Sciences and Medicine, 14 (2), 55-61. DOI: 10.18276/cej.2016.2-06. 
